Brit. J. Ophthal. (1956) 40, 144.

\title{
MACULAR CYSTS: A DOMINANTLY INHERITED AFFECTION WITH A PROGRESSIVE COURSE*
}

BY

\author{
ARNOLD SORSBY, MARY SAVORY, AND J. B. DAVEY \\ Royal Eye Hospital and Royal College of Surgeons \\ AND R. J. LESLIE FRASER \\ Carlisle
}

"HoLEs" at the macula are now generally assumed to be cysts in the central area-in the same way as crater-like "holes" of the disc are recognized as glial cysts at the nervehead. The cystic character of these holes is fairly obvious on ophthalmoscopic examination in some cases, and has been proved in some individual cases by slit-lamp microscopy of the fundus and by pathological examination (Tower, 1954).

In reporting five families with macular cysts, attention is drawn to the fact that the affection is hereditary; that the mode of inheritance is dominant in all these families-it was regularly dominant in three and irregularly dominant in two; and that the condition, largely innocuous at first, is ultimately destructive of central vision.

\section{Case Records}

(1) H-Y FamiLY (Pedigree Chart I). - In this London family a brother and sister were affected in a sibship of seven. Their father is shown as also affected, but in his case the appearances are markedly different.

Case 1, Harry H-y, aged 43 (II, 3, Pedigree Chart I), proband (Fig. Ia,b). Visual acuity: right $6 / 6$, left $6 / 9$ partly. He attended hospital because of some recent blurring of vision in the left eye. In the right eye there was an intact macular cyst, and in the left the macular cyst appeared to have burst. Colour vision: anomalous trichromat, nearly normal. No scotoma in central fields to white object $1 / 2,000 \mathrm{~mm}$.

Case 2, Mrs. C., aged 34 (II, 7), a younger sister. Visual acuity: right 6/6, left 6/9 partly. Here the fundi show intact macular cysts (Fig. 2a,b). The patient was conscious of distortion of objects, and gave a history of transient attacks of this disturbed state of vision on several previous occasions.

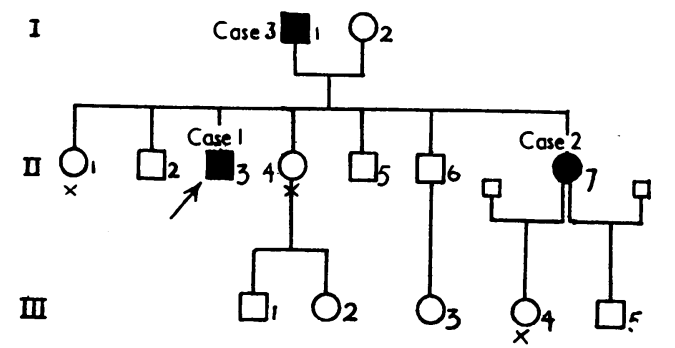

$\square$ Affected $\square_{x} \cdot \bigcirc_{x}$ Unaffected, examined Pedigree Chart I.-H-y family.
Two other sisters (II, 1, and II, 4) were both normal. It proved impossible to see the three brothers (II, 2, 5, and 6).

Case 3, Edward H., aged 79 (I, 1), father of Cases 1 and 2. Visual acuity: $6 / 60$ in each eye. There are considerable lens opacities; details of the right fundus are shown in Fig. 3 , where a central lesion with much outlying disturbance is seen. The fundus in the left eye was essentially similar. His sight had been failing for some 20 years.

* Received for publication November 23, 1955. 
(a)

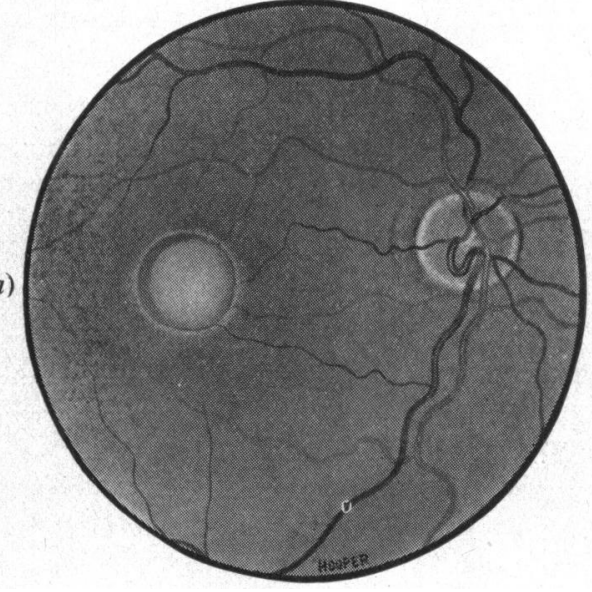

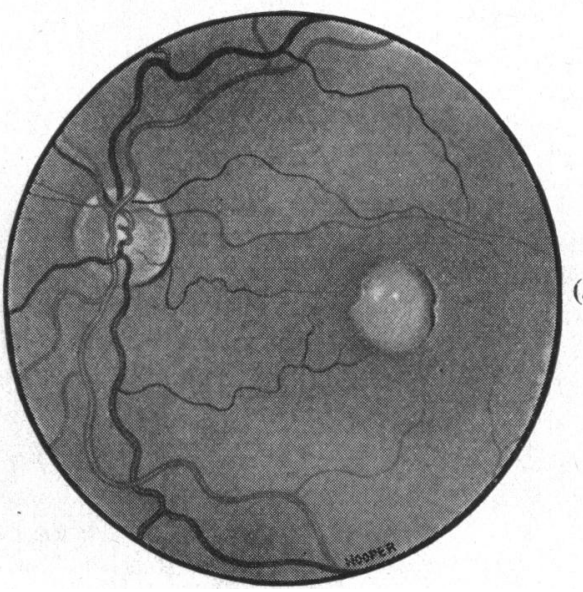

FIG. 1 $(a$ and $b)$. Right and left fundi of Case 1(II,3), a man aged 43. Visual acuity: right $6 / 6$, left $6 / 9$ partly. Vision in the left eye had become blurred only lately. No central field defect, nor marked anomaly in colour vision. Left cyst probably ruptured.
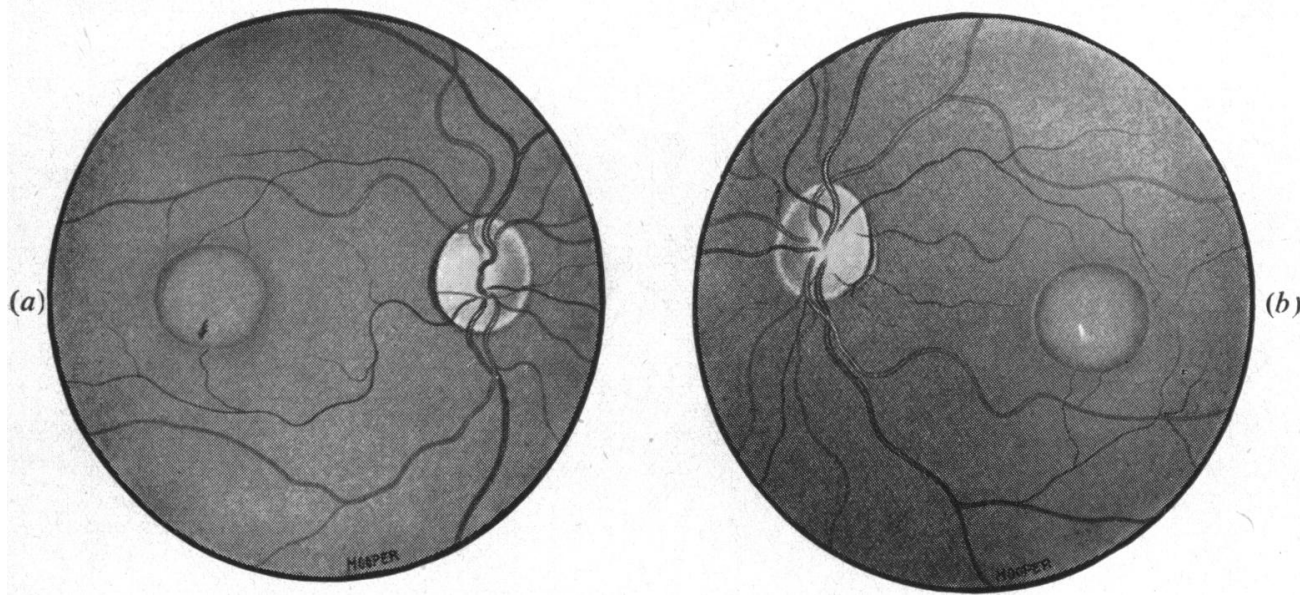

Fig. 2( $a$ and $b$ ).-Right and left fundi of Case 2 (II, 7), a younger sister of Case 1, aged 34 . Visual acuity: right $6 / 6$, left $6 / 9$ partly, recently complicated by distortion of objects. Cysts intact.

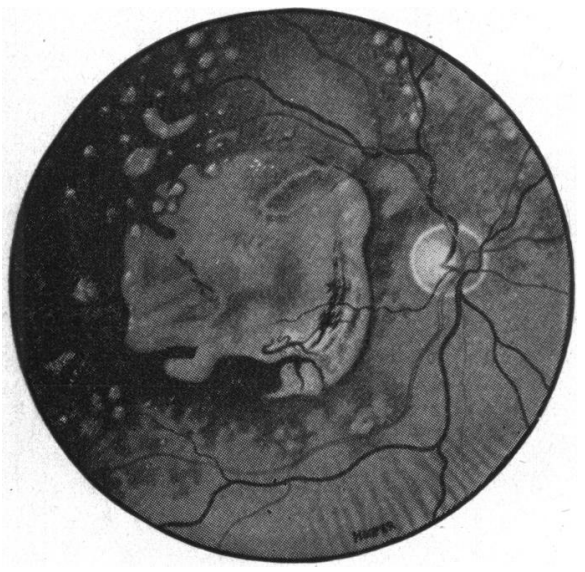

Fig. 3.- Right fundus of Case 3 (I, 1), father of Cases 1 and 2, aged 79. His sight had been failing for some 20 years. Visual acuity: $6 / 60$ in each eye. There are also lens opacities. 
(2) H-N FAMILY (Pedigree Chart II).--In another London family macular cysts were observed in a man and his daughter.

Case 4, Frederick H-n, aged 39 (II, 2, Pedigree Chart II), proband (Fig. 4a,b, opposite). Visual acuity: right $6 / 6$, left $6 / 60$. The patient attended with failing vision in the left eye. There is no great difference between the two eyes, but there is probably more disturbance centrally in the left. He was unaware of any eye trouble in the family. There was no change 4 years later.

Case 5, Pamela H-n, aged 10 (III, 2), daughter of Case 4. Visual acuity: right 6/5, left 6/12, not improved. The fundi (Fig. 5a,b, opposite) show well-marked macular cysts, intact in the left and possibly intact in the right. Peripheral fields normal, dark adaptation normal, colour vision normal to Ishihara test and anomaloscope. The appearances and functions were unchanged 4 years later.

This family proved easier to follow up. A brother (II, 1), two sisters (II, 3 and 4), and the mother (I, 2) of the proband were all found normal, as were a niece (III, 1) and a nephew (III, 3) of the proband. A maternal aunt of the proband was also found normal. The father of the proband (I, 1) had been killed in France in 1918 at about the age of 50; he was reported by one of his daughters to have had poor sight in one eye.

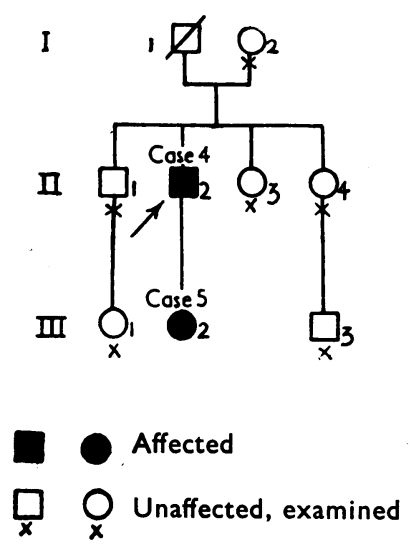

Pedigree Chart II.-H-n family.

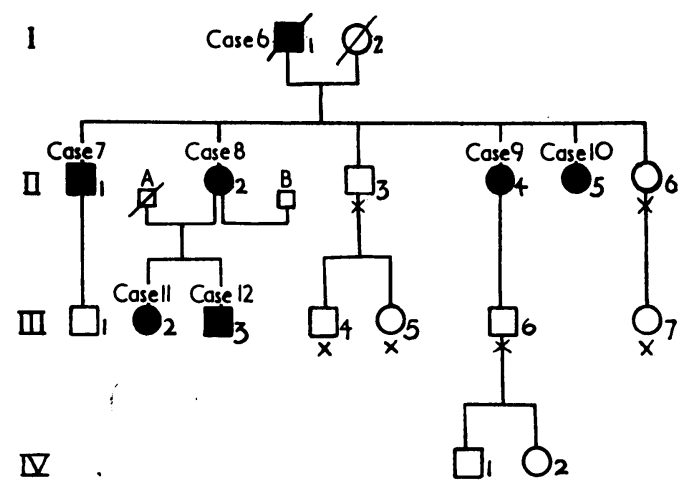

$\square$ Affected $\square_{x} \bigcirc_{x}$ Unaffected, examined

Pedigree Chart III.-C-ns family.

(3) C-NS FAmILY (Pedigree Chart III).--In this Cumberland family there were seven cases over three generations.

Case 6, Henry C-ns (I, 1), who died at 74, had been known as affected to Dr. J. A. Ross of Carlisle.

Case 7, John C-ns, aged 57 (II, 1), son of I, 1, showed macular cysts in both fundi. Visual acuity : 6/9 in each eye.

*Case 8, Mrs. Mary J., aged 55 in 1951 (II, 2), daughter of I, 1, had had failing sight for 20 years. Visual acuity: with glasses +1.75 D $5 / 60$ in each eye. Normal colour vision, defective dark adaptation on both the cone and the rod curves (Fig. A, opposite). There was restriction of the peripheral fields. The fundi show macular cysts with considerable central changes but no surrounding pigment reaction. Fig. 6 (overleaf) shows the appearances in the right eye; the left eye was similar. *It should be noted that Case 8 and her two children, Cases 11 and 12, are highly apprehensive and that the findings
at all their subjective tests are rather open to question. 

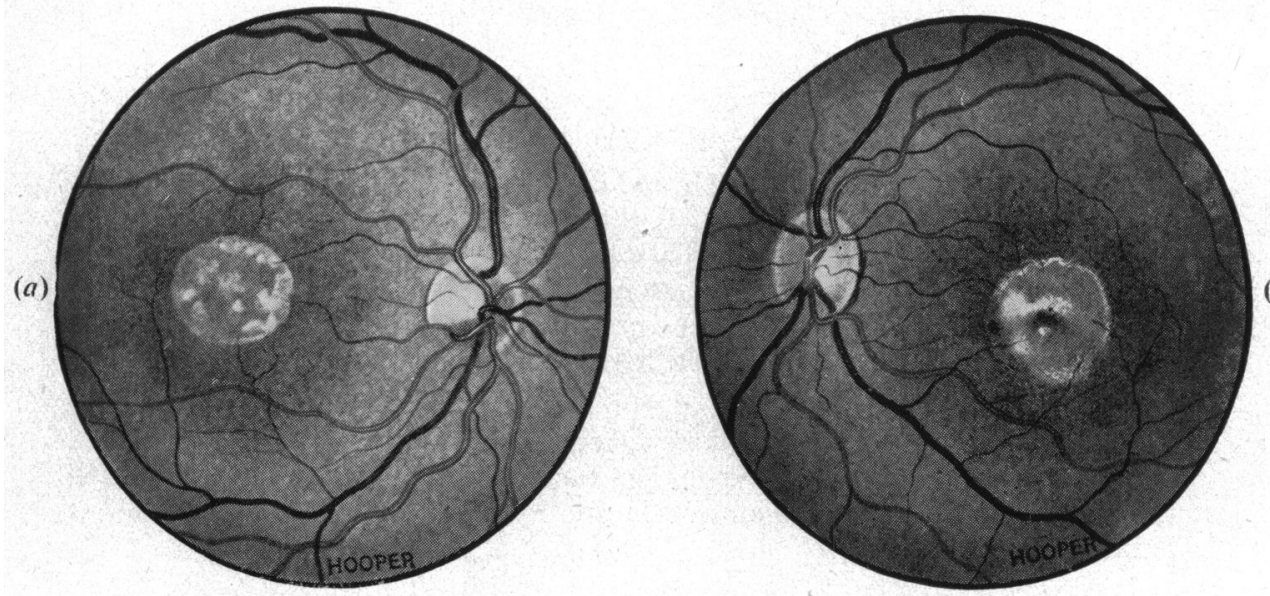

Fig. 4( $a$ and $b)$. - Right and left fundi of Case 4 (II, 2), a man aged 39. Visual acuity: right $6 / 6$, left $6 / 60$. Left cyst probably ruptured. No change observed over 4 years.

(a)

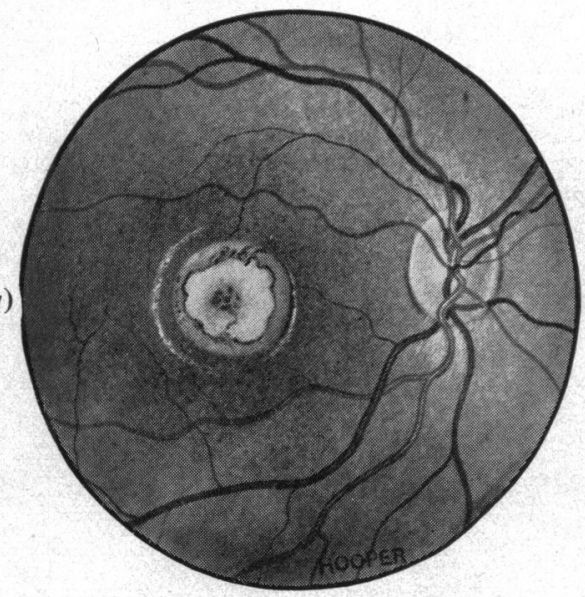

(b)

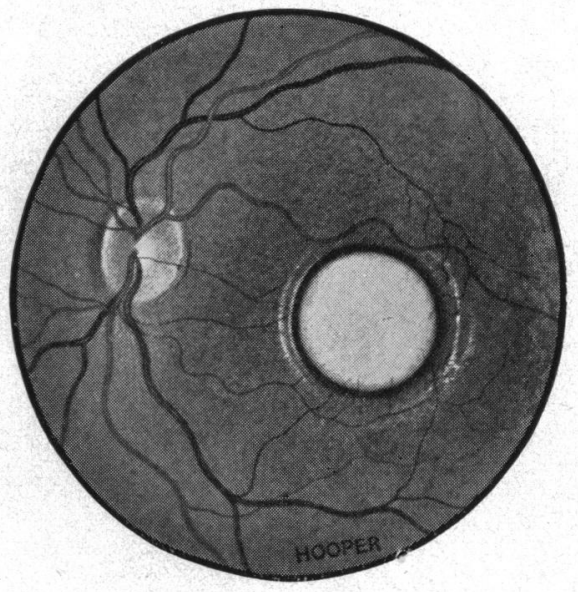

(b)

FIG. 5( $a$ and $b)$.-Right and left fundi of Case 5 (III, 2), 10-year-old daughter of Case 4. Visual acuity: right 6/5, left 6/12. Dark adaptation and colour vision normal.

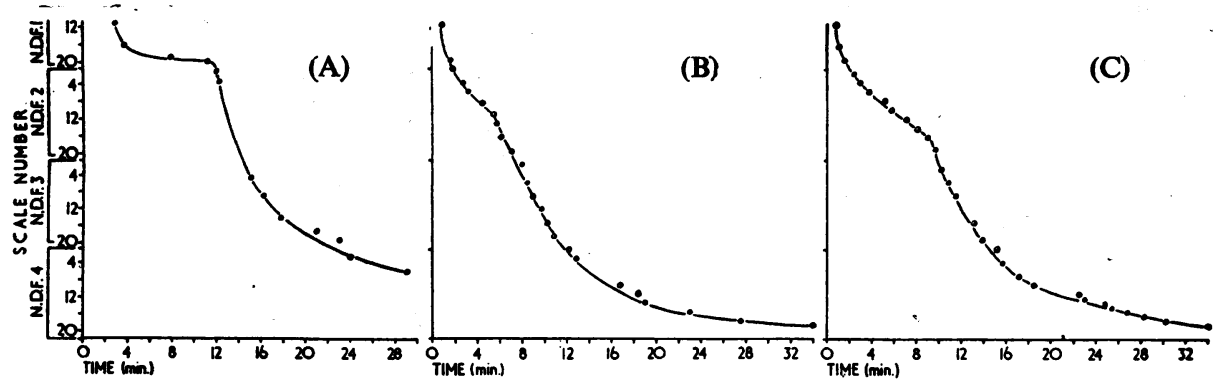

FIG. A.-Dark adaptation curve of Case 8 (II, 2 in Pedigree Chart III), aged 55 (right fundus shown in Fig. 6). There is defective dark adaptation as shown by both the cone and the rod curves.

Fig. B.-Dark adaptation curve of Case 11 (III, 2 in Pedigree Chart III), aged 18 (right fundus shown in Fig. 7). Both cone and rod curves are within normal limits. FIG. C.-Dark adaptation curve of Case 12 (III, 3 in Pedigree III), aged 16 (left fundus shown in Fig. 8). Dark adaptation poor in cone curve. . 
Case 9, Mrs. Elizabeth E., aged 45 (II, 4). Visual acuity: right 6/18, left 6/12. Both fundi show macular cysts.

Case 10, Mrs. Ada S., aged 37 (II, 5). Both fundi show macular cysts. The appearances are similar to those seen in her elder sister, (II, 2).

*Case 11, Majorie D., aged 18 (III, 2), daughter of II, 2. Visual acuity: right 'with glasses $+4 \mathrm{D}$ sph., $-0.5 \mathrm{D}$ cyl. $30^{\circ}, 6 / 18$; left $+3.75 \mathrm{D}$ sph., $-0.5 \mathrm{D}$ cyl. $150^{\circ}$, 6/18. Peripheral fields of vision full, dark adaptation within normal limits (Fig. B). On the Ishihara plates the response was irregular, not conforming to any of the known colour defects; on the anomaloscope the patient was red defective. Fig. 7 shows the fundus appearances in the right eye, the left eye was similar.

*Case 12, Robert D., aged 16 (III, 3), son of II, 2. Visual acuity: right 6/36, left 6/60. Peripheral fielos restricted, dark adaptation poor in the cone curve (Fig. C). The patient was totally colour blind on the Ishihara plates, and strongly red defective on the anomaloscope. The fundus of the left eye is shown in Fig. 8; the right eye was similar.

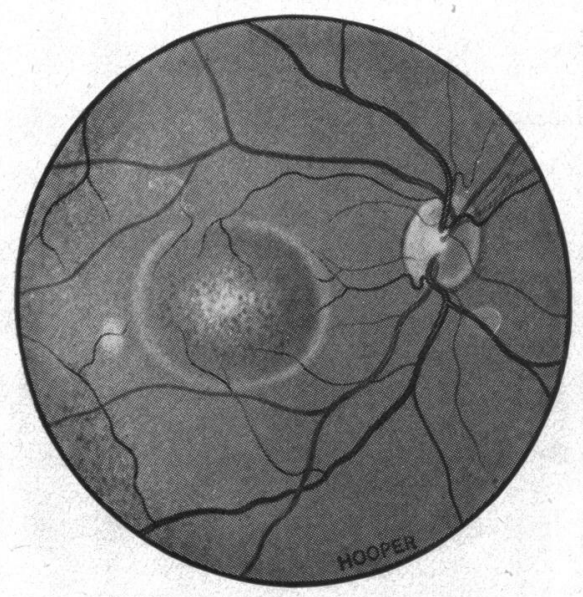

Fig. 6.-Right fundus of Case 8 (II, 2), a woman aged 55, whose sight has been failing for 20 years. Visual acuity: 5/60 each eye. Left fundus similar, dark adaptation defective, colour vision normal.
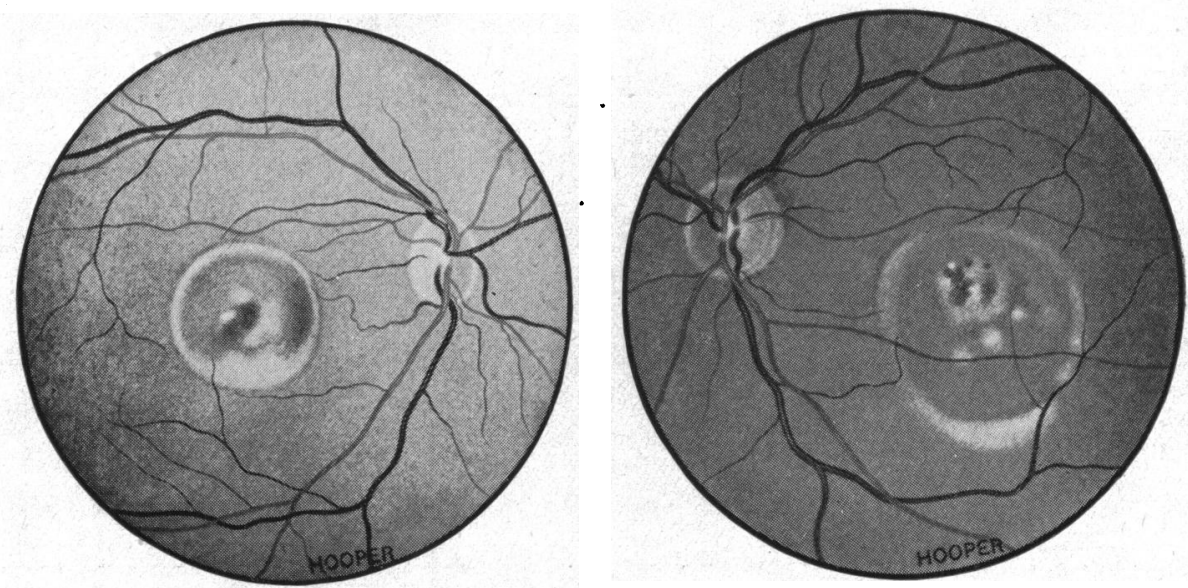

Fig. 7.-Right fundus of Case 11 (III, 2), 18-year-old daughter of Case 8. Visual acuity: 6/18 each eye. Left fundus similar, dark adaptation normal, some disturbances in colour vision.

Fig. 8.-Left fundus of Case 12 (III, 3), 16-year-old brother of Case 11, and son of Case 8. Visual acuity: right $6 / 36$, left $6 / 60$. Right fundus similar, disturbances in dark adaptation and colour vision. 
Apart from these three families with direct inheritance over two generations in two families, and over three generations in a third family, two further families showed apparently irregular dominance.

(4) C. Family (Pedigree Chart IV).-In this London family two sisters, aged 10 and 9, showed macular cysts in both eyes. A similar lesion was seen in their

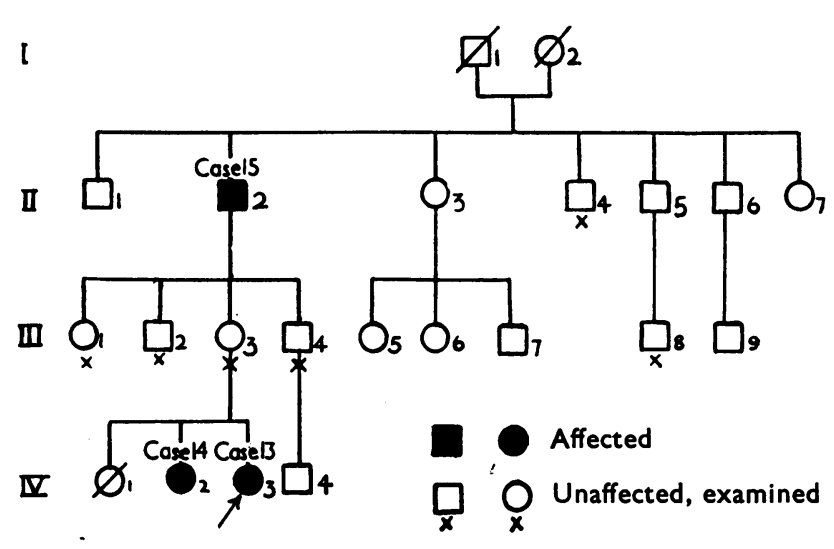

Pedigree Chart IV.-C. family. maternal grandfather, the mother herself being normal, and the family history otherwise clear.

Case 13, Carol S., aged 9 (IV, 3), the proband. Visual acuity right $6 / 12$, left $6 / 36$, not improved. Both fundi show macular cysts; the right has either burst or is on the point of bursting (Fig. 9e,f, overleaf).

Case 14, Jennifer S., aged $10(\mathrm{IV}, 2)$. Visual acuity: right $6 / 9$, left $6 / 6$. The macular cysts are obvious and possibly the right has already ruptured (Fig $9 c, d$, overleaf).

Case 15, Mr. B. C., aged 63 (II, 2), the maternal grandfather of these children, is a dental surgeon. Visual acuity: with glasses $+0.75 \mathrm{D}$ sph. 6/36 in each eye, not improved. The fundi (Fig. 9a,b, overleaf) show two punched-out areas in the macular region with exposure of the choroidal vessels and some pigmentary disturbance-presumably macular cysts that have ruptured, and the anterior wall probably absorbed. The patient first noticed difficulty with the left eye about 15 years ago, and vision has become slowly worse in both. He is still able to do his work with some difficulty.

(5) B. FAMILY (Pedigree Chart V).-In this London family the Scottish mother of the proband showed only a doubtfully pathological fundus, though a collateral branch living in Scotland was affected.
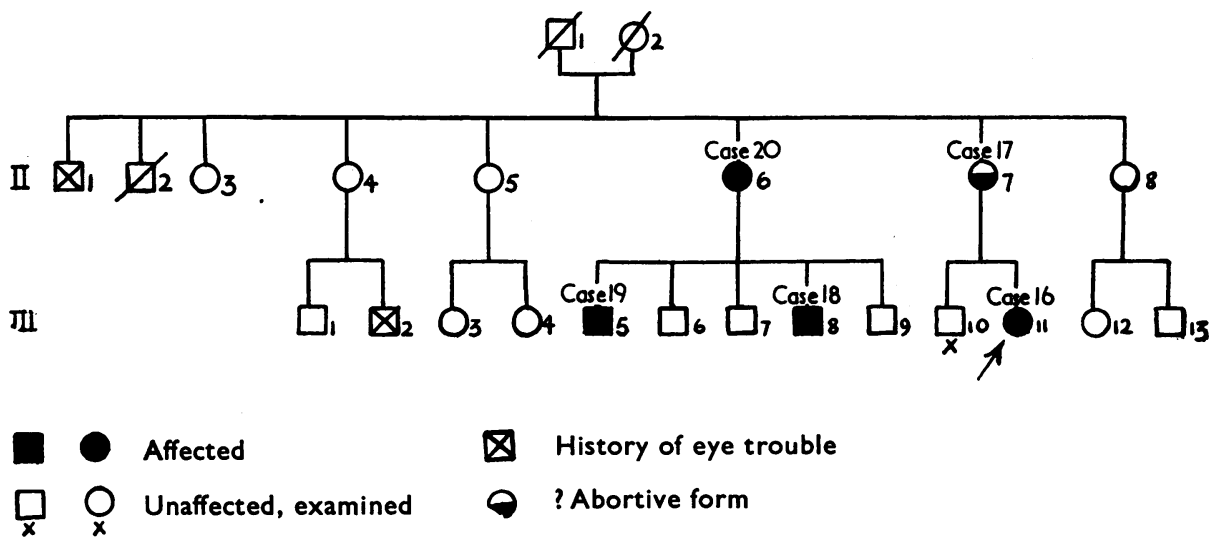

Pedigree Chart V.-B. family. 

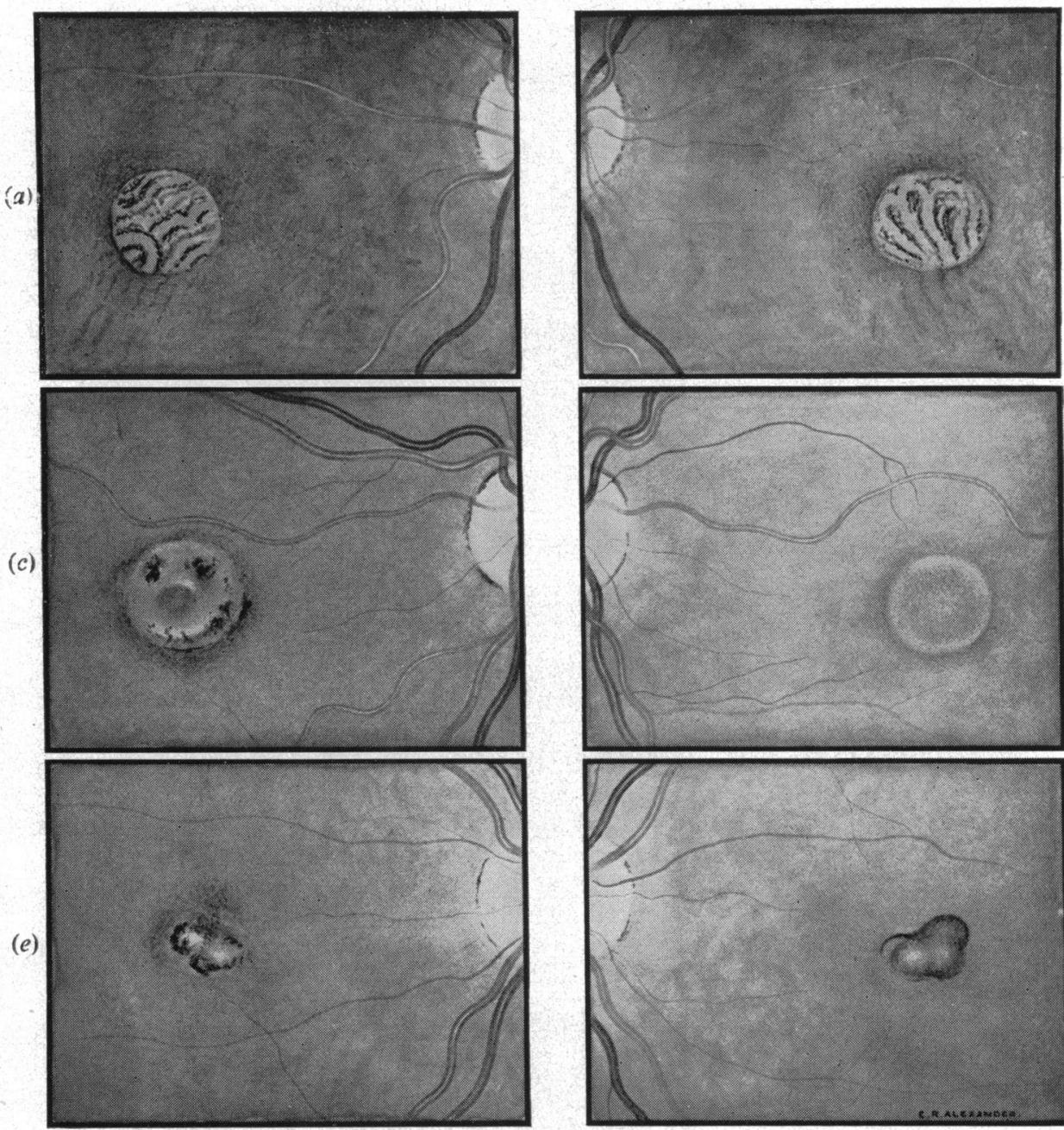

(b)
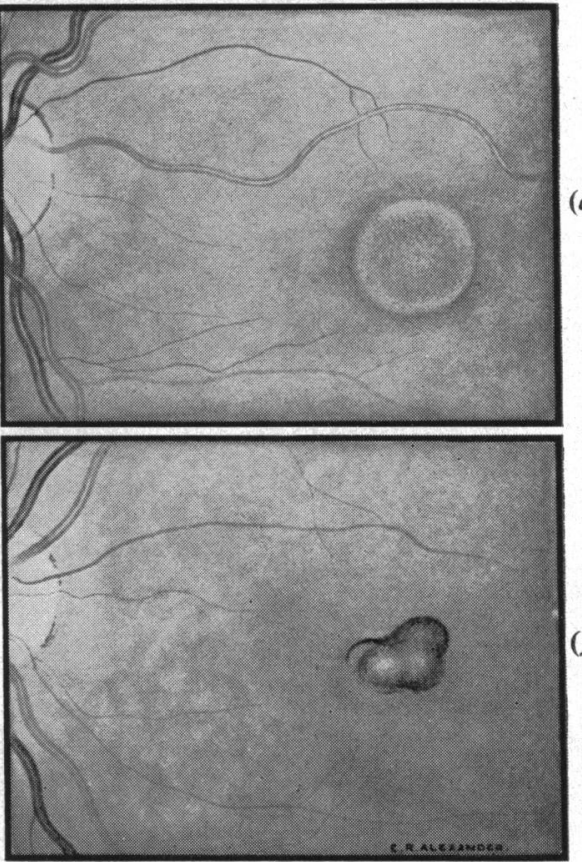

Fig. 9( $a$ and $b)$.--Right and left fundi of Case 15 (II, 2), a man aged 63, whose sight had been failing for some 15 years. Visual acuity: 6/36 each eye. The appearances are taken to mean a ruptured macular cyst with some atrophy of the retina and pigment epithelium, and consequent exposure of the chorio-capillaris.

FIG. 9(c and $d)$.-Right and left fundi of Case 14, (IV, 2), 10-year-old granddaughter of Case 15 . Visual acuity: right 6/9, left 6/6. ? Rupture of right cyst. Fig. $9(e$ and $f)$.-Right and left fundi of Case 13 (IV, 3), younger sister of Case 14. Visual acuity: right $6 / 12$, left $6 / 36$. Right cyst probably ruptured.

Case 16, Miriam B., aged 17 (III, 11), the proband, was first seen at the age of 7 when visual acuity was right $6 / 9$, left $6 / 36$, refraction: $+2 \cdot 50 \mathrm{D}$ sph. in each eye. At the age of 12 , it was right $6 / 9$ partly and left $6 / 12$ partly with $+1.5 \mathrm{D}$ sph. in each eye; it has remained unchanged since. At the age of 3 she had poliomyelitis, which left a crippling defect in the right leg. The fundi show characteristic macular cysts with much surrounding pigment reaction (Fig. 10c,d, opposite).

Case 17, Mrs. W. B., aged 42 (II, 7), mother of the proband, had full vision and an unusual central fundus lesion in both eyes (Fig. 10a,b, opposite): a diffuse fine 
(a)

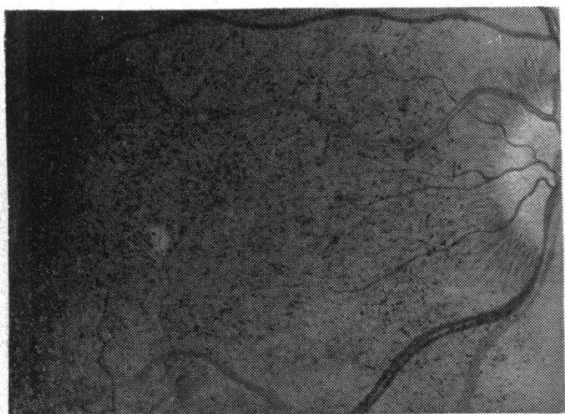

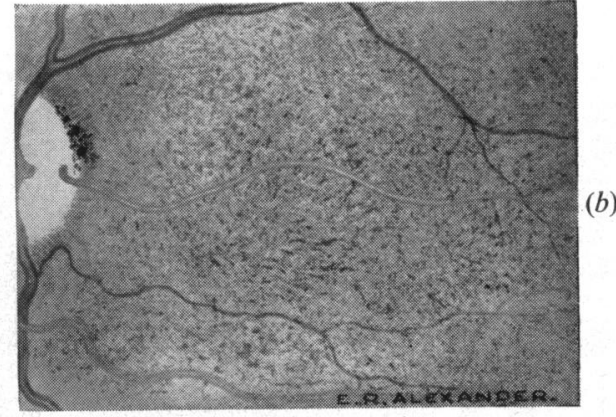

(b)

FIG. 10( $a$ and $b)$.- -Right and left fundi of Case 17 (II, 7), a woman aged 42 . Vision full, diffuse mottling throughout posterior pole. Her nephew, Case 18 (III, 8), and her daughter, Case 16 (III, 11), figured below, both show macular cysts.
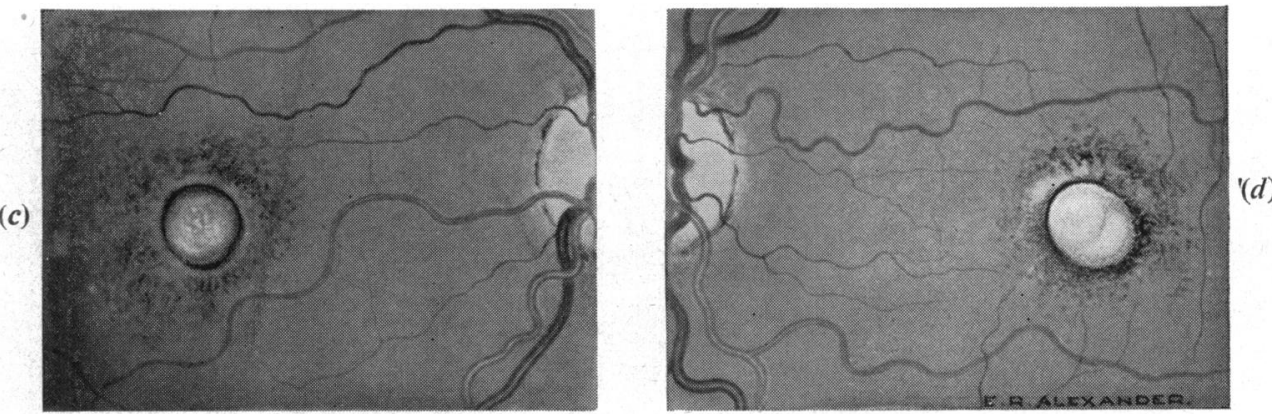

Fig. 10(c and $d)$.- Right and left fundi of Case 16 (III, 11), when aged 14, daughter of Case 17. Visual acuity: right 6/9 partly, left $6 / 12$ partly. This girl, now aged 17, has been under observation for some 10 years and has shown no substantial changes.

pigmentation throughout the posterior pole, with a small atrophic patch temporal to the macular in the right. The patient was unaware of any trouble, nor could any anomalies be revealed by tests.

A further search throughout the family was hampered by geographical factors. However, the existence of a similar lesion in a collateral branch of the family, the mother's sister (Case 20) and two of her sons (Cases 18 and 19), was almost certain.

Case 18, James S., aged 13 (III, 8), was seen at the Edinburgh Royal Infirmary at the age of 6 with a corneal abrasion in the right eye. Subsequently notes on changes at the maculae were recorded: " the right macular area shows two areas of pallor just below the macula which appear to be slightly elevated." The left macula is noted as showing "large holes". Visual acuity: right 6/12, left 6/6 partly. A year later there is a note that there was eye trouble in a brother and a maternal uncle. Two years later vision had remained unchanged.

Case 19, Robert S., aged 20 (III, 5). In 1951, when he was 18, visual acuity was right $6 / 9$, left $6 / 24$; " a patch of choroidal atrophy with pigmentation in both macular areas" was noted.

Case 20, Mrs. Mary S., aged 44 (II, 6), mother of Cases 18 and 19. In 1952 visual acuity was right $6 / 24$, left $6 / 60$. The fundi showed "macular degeneration in both eyes and also some pepper and salt changes in the periphery". 


\section{Discussion}

Cyst formation at the macula may be the response to a number of different stimuli. Trauma is an obvious cause in some unilateral cases, and vascular disturbances in others. The complexity of the problem is well brought out in the recent discussion by Tower (1954), whilst the possibility that bilateral cysts may be genetic in origin and progressive in course has been indicated elsewhere (Sorsby, 1951). A report of five cases in one family over three generations by McFarland (1955) probably relates to macular cysts; a lesion described"as " a round elevated area which assumes a cystic configuration", Type II of the classification of macular dystrophies by Klien (1950), was observed in the younger members, whilst a central reaction was seen in the older members.

Bilateral macular cysts as a genetic entity has fairly clear-cut features. On the basis of the cases reported here the following account is warranted.

\section{Clinical Course}

Onset.-The affection is probably congenital in type. This is suggested by the fact that eight of the twenty cases studied here were under the age of 20 , though it is worth noting that the youngest patient in this series was 9 years old. The congenital nature of the affection therefore still remains to be proved.

Effect on Vision.-Excluding Case 10 because of an incomplete record, and Case 3 because of the presence of considerable lens opacities, there are eighteen cases left, ranging in age from 9 to 63 years.

Of six cases between the ages of 43 and 63, four have vision below 6/24; only two (Cases 7 and 1) have good vision. Case 17, aged 42, has full vision, but probably represents the carrier state rather than the affection.

The remaining eleven cases are all under the age of 40 , and only one has poor vision (Case 12, a boy of 16 , who was not an entirely reliable witness). All the others have moderately good vision, though several have defective vision in one eye.

Failing vision is therefore to be expected only in middle life; there was a history of failing vision for 15 years in Case 15 (a man aged 63), for 20 years in Case 8 (a woman aged 55), and only " lately " in Case 4 (a man aged 39). Cases 7 and 1 do, however, emphasize that failure of vision need not necessarily occur.

Associated Disturbances.-The findings recorded for Cases 1 and 5 do not suggest any changes in dark adaptation and colour vision as part of the clinical picture. In the third family with severe visual disturbances, anomalies in colour vision and in dark adaptation were, however, present.

McFarland (1955) recognized the progressive character of the cysts seen in the younger members in his family. His findings agree fairly closely with those seen in the C. family (Pedigree Chart IV) recorded here. 


\section{Ophthalmoscopic Appearances}

Ophthalmoscopically cysts vary in size and appearance, but there is a distinct intra-familial similarity. Thus the cysts in the first and fourth families are all about one disc diameter in size, whilst those in the second and third families are larger. Within a family the different members may, however, show some considerable variations, and there may also be differences between the two eyes. At the end-stage, when there is much secondary atrophy, it may be difficult to visualize the original size of the cyst; this is suggested by Fig. 3 compared with Figs 1 and 2. Sometimes the cystic nature of the lesion is obvious, but frequently there is much pigmentary and atrophic reaction in the central area, and but little suggestion of a cyst. In any particular case a definite diagnosis as to the cystic nature of the lesion may be exceedingly difficult on ophthalmoscopic evidence only. Taking the appearances shown in Fig. 3 and in Fig. $9 a$ and $b$ as representing the endstage, it must be accepted that this is no longer cystic in character. The cysts have apparently burst, their anterior wall has become absorbed and a variable amount of destruction of tissue and of pigmentation has occurred.

\section{Mode of Inheritance}

Dominant inheritance is suggested by the first three pedigrees, though conclusive evidence is available only from Pedigree Chart III, where the affection has been known to occur over three generations in direct descent. In the light of these findings the inheritance recorded in Pedigree Chart IV must be interpreted as once again dominant, without expression in the second generation. Variation in expression is shown in Pedigree Chart V, where II, 7 is clinically silent and ophthalmoscopically anomalous.

The data on the occurrence of the affection in these five family groups are shown in the Table.

TABLE

DISTRIBUTION OF AFFECTED AND UNAFFECTED MEMBERS OF THE FIVE FAMILIES STUDIED

\begin{tabular}{|c|c|c|c|c|c|c|c|c|c|c|c|c|c|}
\hline \multirow{2}{*}{ Family } & \multirow{2}{*}{$\begin{array}{c}\text { Genera- } \\
\text { tion }\end{array}$} & \multicolumn{3}{|c|}{ Affected } & \multicolumn{3}{|c|}{ Unaffected } & \multicolumn{3}{|c|}{ Not Known } & \multicolumn{3}{|c|}{ Totals } \\
\hline & & Male & Female & Total & Male & Female & $\overline{\text { Total }}$ & Male & Female & Total & Male & Female & Total \\
\hline H-y & III & 1 & 1 & 2 & $=$ & $\begin{array}{l}2 \\
1\end{array}$ & $\begin{array}{l}2 \\
1\end{array}$ & $\begin{array}{l}3 \\
2\end{array}$ & $\overline{2}$ & $\begin{array}{l}3 \\
4\end{array}$ & $\begin{array}{l}4 \\
2\end{array}$ & $\begin{array}{l}3 \\
3\end{array}$ & $\begin{array}{l}7 \\
5\end{array}$ \\
\hline H-n* & III & - & 1 & 1 & - & - & - & - & - & - & - & 1 & 1 \\
\hline C-ns & $\underset{\text { III }}{\text { II }}$ & $\begin{array}{l}1 \\
-\end{array}$ & $\begin{array}{r}3 \\
1 \\
-\end{array}$ & $\begin{array}{r}4 \\
2 \\
-\end{array}$ & $\begin{array}{r}1 \\
- \\
-\end{array}$ & $\begin{array}{r}1 \\
-\end{array}$ & $\begin{array}{r}2 \\
4 \\
-\end{array}$ & $\overline{1}$ & $\overline{\overline{1}}$ & $\overline{\mathbf{1}}$ & $\begin{array}{l}2 \\
4 \\
1\end{array}$ & $\begin{array}{l}4 \\
3 \\
1\end{array}$ & $\begin{array}{l}6 \\
7 \\
2\end{array}$ \\
\hline C.t & III & $=$ & $\overline{2}$ & $\overline{2}$ & $\underline{2}$ & 2 & 4 & $\overline{1}$ & $\overline{1}$ & $\overline{2}$ & $\begin{array}{l}2 \\
1\end{array}$ & 2 & $\begin{array}{l}4 \\
4\end{array}$ \\
\hline B. & III & $\overline{2}$ & $\begin{array}{l}2 \\
1\end{array}$ & 2 & $\overline{1}$ & $=$ & $\overline{1}$ & 2 & 4 & $\begin{array}{l}6 \\
3\end{array}$ & $\begin{array}{l}2 \\
6\end{array}$ & $\begin{array}{l}6 \\
1\end{array}$ & $\begin{array}{l}8 \\
7\end{array}$ \\
\hline Totals & & 5 & 11 & 16 & 6 & 8 & 14 & 13 & 8 & 21 & 24 & 27 & 51 \\
\hline
\end{tabular}

* As there is no evidence that the affection was present in the first generation, and the possibility arises that the case in the second generation represents a mutation, only Generation III was considered here.

+For a similar reason Generation II in this family is omitted from the analysis. 
It is seen that there were sixteen known cases of the affection against fourteen known normals (with 21 individuals who could not be examined). This is consistent with the $1: 1$ ratio expected in dominance. There was a female excess amongst both affected and unaffected, but neither is statistically significant. It may therefore be taken that the mode of inheritance is simple dominance with variable expression and high, though incomplete, penetrance.

The possibility of a recessive sex-linked type of macular cyst is suggested by the brief report by Falls (1952) in a study on sex-linkage. Identical twin boys showed macular cysts; their mother was normal whilst two, and possibly three, of her brothers had "macular degeneration".

\section{Differential Diagnosis}

At the Cystic Stage.-Before degenerative changes set in the cystic character of the affection is obvious and differential diagnosis presents little difficulty. Two affections, Best's disease and macular dystrophy, have to be considered:

BEST'S DiSEASE.-First observed by Best (1905), and subsequently followed up in the same family by Vossius (1921), by Weisel (1922), and by Jung (1937), this affection has only one other report in the literature-that by Falls (1949) of an American family. Best's disease is probably a congenital disturbance, and-judging by the accounts in the literature-it is not unlikely that families with macular cysts were actually being studied. It is consistent with this reading that in the two families observed the affection was dominant, and vision was frequently good in affected members.

MACUlar DYSTROPHY.-It is also likely that some of those reported in the literature as cases of macular dystrophy were in fact cases of macular cysts. Judging by the published illustrations, such cases occurred in families reported by Behr (1920), Chance (1920), Alkio (1923), and Sorsby (1940). That some macular dystrophies are also dominant has been shown in a recent study (Sorsby and Davey, 1955). A differential diagnosis between dominant macular dystrophy and macular cyst may be all the more difficult in uncharacteristic cases, as dominant macular dystrophy also may be relatively symptomless for many years.

At the Degenerative Stage.-Differential diagnosis presents considerable difficulty in the degenerative stages of macular cyst. Here the cystic character of the affection is no longer obvious and an uncharacteristic macular lesion is all that may be seen. In such cases diagnosis may be possible only with a full family investigation. Moreover the degenerative stages of the affection are only sketchily known and further studies are needed.

\section{Histology}

If the family which is reported by McFarland (1955) is regarded as one showing macular cysts, the histological appearances in his eldest patient are 
of interest. A report by Klien (1950) describes the lesion as an extensive defect of the first neuron, with the pigment epithelium missing over a rather smaller area than that of the retinal defect-the affected pigment epithelium and neuro-epithelium being replaced by a glial membrane. Bruch's membrane showed calcification and ruptures near the nervehead, whilst the chorio-capillaris was absent and the large choroidal vessels showed marked sclerosis of the involutionary type-changes regarded as due to senile degeneration co-existent with a retinal lesion of the juvenile dystrophic type.

\section{Some Implications}

The present study adds one further clinical entity to the dominant central fundus lesions: macular coloboma, macular dystrophy, central choroidal sclerosis, generalized fundus dystrophy, Doyne's disease, and Best's disease (if this latter be accepted as a separate entity). Of these affections, the congenital nature is obvious in macular coloboma, and is likely in macular cysts (and possibly Best's disease). In contrast macular dystrophy, central choroidal sclerosis, generalized fundus dystrophy, and Doyne's disease develop in post-natal life. Of these six (or possibly seven) dominant affections, two-macular dystrophy and central choroidal sclerosis-have recessive variants. All these affections, excluding macular coloboma, are progressive, though to a variable extent.

\section{Summary}

(1) Five families of dominantly inherited, bilateral macular cysts are reported. In two families observations extended over three generations and in three over two generations.

(2) Regular dominance was observed in four families; in the fifth the mother of two affected daughters was normal, though her father was affected.

(3) The affection shows the following features:

(a) It is probably congenital in character.

(b) There is nothing to suggest subjective change in the central fields, colour vision, and dark adaptation, during the quiescent stages of the affection.

(c) Visual disturbances tend to develop in middle-age and are probably only slowly progressive. These disturbances appear to be determined by rupture of the cyst, followed by slow pigmentary degenerative changes, including the absorption of the anterior wall of the cyst.

(d) At the end-stage - presumably towards the seventh decade of lifea non-pathognomonic macular lesion is seen.

(e) The ophthalmoscopic appearances show both considerable intrafamilial similarity and inter-familial variation. An occasional variant of macular cyst is a non-pathognomonic pigmentation of the central fundus area. 
(4) The differential diagnosis from other dominant central fundus lesions is indicated.

Mr. C. J. Longworth Blair of Richmond referred the third family to us, and Mr. J. A. Chivers of Orpington the fourth family. Dr. Ruby Joseph helped in investigating the first two families, and Dr. J. Macaskill supplied information on Cases 18, 19, and 20, seen at the Edinburgh Royal Infirmary. To them all our thanks are due.

\section{REFERENCES}

Alkio, V. V. (1923). Acta ophthal. (Kbh.), 1, 27.

BEHR, C. (1920). Klin. Mbl. Augenheilk., 65, 465.

BEST, F. (1905). Z. Augenheilk., 13, 199.

CHANCE, B. (1920). Amer. J. Ophthal., 3, 241.

Falls, H. F. (1949). Amer. J. hum. Gen., 1, 96.

(1952). Trans. Amer. ophthal. Soc., 50, 435.

JuNG, E. E. (1937). "Ueber eine Sippe mit angeborener Maculadegeneration". Thesis, Giessen.

Klien, B. A. (1950). Amer. J. Ophthal., 33, 370.

MCFARLAND, C. B. (1955). A.M.A. Arch. Ophthal., 53, 224.

SORSBY, A. (1940). British Journal of Ophthalmology, 24, 469. (1951). "Genetics in Ophthalmology", p. 156. Butterworth, London. and DAVEY, J. B. (1955). British Journal of Ophthalmology, 39, 257.

Tower, P. (1954). "Observations on Hole in the Macula". Bibliotheca Ophthalmologica, Suppl. to Ophthalmologica (Basel), Fasc. 40. Karger, Basel.

Vossius, A. (1921). v. Graefes Arch. Ophthal., 105, 1050.

WEISEL, G. (1922). “ Beitrag zur Bestschen hereditaren Maculaerkrankung ”. Thesis, Giessen.

\section{APPENDIX}

The following information additional to that shown in the Pedigree Charts is available:

\section{(1) The H-y family}

Generation I

1. Edward H-y, aged 80 (Case 3).

2. Mrs. H-y, mother of proband, aged over 70 , diabetic, sight said to be bad.

Generation II

1. Mrs. Elsie W., aged 45, examined, unaffected.

2. Ted $\mathrm{H}-\mathrm{y}$, aged 43 .

3. Case 1, proband.

4. Mrs. S., aged 40, examined, unaffected.

5. Bert $\mathrm{H}-\mathrm{y}$, aged 37.

6. Leonard $\mathrm{H}-\mathrm{y}$.

7. Case 2.

Generation iII

1. Child, aged 14.

2. Child, aged 4.

3. Child, aged 4.

4. Theresa, aged 11, examined, unaffected.

5. Child, aged $4 \frac{1}{2}$.

\section{(2) The H-n family}

Géneration I

1. - H-n, died aged 50.

2. Mrs. Mary H-n, mother of proband, aged 65 . Visual acuity: right 6/18, left 6/12. Early lens changes, colour vision normal, fundi normal.

3. - maternal aunt of proband, sister of I, 2 .

Generation II

1. Edward H-n, aged 41. Visual acuity, with glasses, right +4 D 6/6; left +3.52 D 6/9 Colour vision normal, some slight disturbance at each macula. 
2. Case 4, proband.

3. Margery H-n, aged 37. Visual acuity: $6 / 4$ both eyes. Colour vision normal, fundi normal.

4. Mrs. - H-t, aged 32.

Generation III

1. Valerie H-n, aged 10.

2. Case 5.

3. Michael H-t, aged 9 . Visual acuity $6 / 5$ both eyes. Colour vision normal, fundi normal.

\section{(3) The C-ns family}

\section{Generation I}

1. Case 6.

2. Mrs. Elizabeth C-ns, died aged 77.

\section{Generation II}

1. Case 7.

2. Case 8.

A. First husband of II, 2, Arthur W. D., died aged 64.

B. Second husband of II, 2, Mr. J.

3. Harry C-ns, aged 47 , examined, unaffected.

4. Case 9.

5. Case 10.

6. Mrs. Lilian Y., aged 35, examined, unaffected.

\section{Generation III}

1. Kenneth C-ns, known to have served in R.A.F.

2. Case 11.

3. Case 12.

4. Keith C-ns, aged 20, examined, unaffected.

5. Christine C-ns, aged 8, examined, unaffected.

6. Raymond E., examined, unaffected.

7. Kathleen Y., aged 2, examined, unaffected.

\section{Generation IV}

1. Raymond E., aged 2.

2. Sandra $E_{0}$, aged 1.

\section{(4) The C. family}

\section{Generation II}

1. Harry C., aged 65.

2. Case 15.

3. Mrs. Winifred St., aged 61 .

4. Frank C., aged 60, examined, unaffected.

5. John C., aged 58.

6. Eric C., aged 52.

7. Mrs. Gladys C., aged 50.

\section{Generation III}

1. Miss - C., aged 38, examined, unaffected.

2. - C., aged 36, examined, unaffected.

3. Mrs. Phyllis J. S., aged 35, examined, unaffected.

4. Ronald C., aged 32, examined, unaffected.

8. John C., aged 10.

\section{Generation IV}

1. Died at birth.

2. Case 14.

3. Case 13, proband.

4. Peter C., aged 4. 
(5) The B. family

Generation I

1. and 2. Mr. and Mrs. D,, both dead, at about 50 and 60 years respectively. No consanguinity.

\section{Generation II}

1. Jim D., aged 56, eye trouble.

2. Died aged 31 .

3. Mrs. Ann McI., aged 52.

4. Mrs. Betty B., aged 50.

5. Mrs. Ellen -, aged 47 (in Canada).

6. Case 20.

7. Case 17.

8. Mrs. I. C., aged 40.

Generation III

3 and 4 . aged 16 and 13 respectively.

5. Case 19.

6. William S., aged 20.

7. Charles S., aged 16.

8. Case 18.

9. - S., aged 6.

10. James B., aged 18, examined, unaffected.

11. Case 16, proband. 